14,15

\title{
Композитные пленки на основе углеродных квантовых точек в матрице проводящего полимера PEDOT : PSS
}

\author{
(ㄷ Г.В. Ненашев ${ }^{1}$, М.С. Истомина ${ }^{2,3}$, И.П. Щербаков ${ }^{1}$, А.В. Швидченко ${ }^{1}$, В.Н. Петров ${ }^{1}$, А.Н. Алешин ${ }^{1,9}$ \\ ${ }^{1}$ Физико-технический институт им. А.Ф. Иоффре, \\ Санкт-Петербург, Россия \\ ${ }^{2}$ Санкт-Петербургский государственный электротехнический институт „ЛЭТИ“, \\ Санкт-Петербург, Россия \\ ${ }^{3}$ Национальный медицинский исследовательский центр им. В.А. Алмазова, \\ Санкт-Петербург, Россия \\ ๑ E-mail: aleshin@transport.ioffe.ru
}

Поступила в Редакцию 14 апреля 2021 г.

В окончательной редакции 14 апреля 2021 г.

Принята к публикации 18 апреля 2021 г.

\begin{abstract}
Получены гидротермальным методом из глюкозы углеродные квантовые точки (УКТ; carbon quantum dots - CQDs), а также их композиты с проводящим полимером PEDOT: PSS и исследованы их электрические свойства в диапазоне температур 77-280K. Показано, что пленки УКТ и PEDOT: PSS-CQDs имеют глобулярную структуру с размерами глобул $\sim 50 \mathrm{~nm}$. Получены зависимости удельного сопротивления от температуры, $\rho(T)$, для пленок УКT, PEDOT:PSS-CQDs и PEDOT:PSS, имеющие слабый активационный характер. При этом установлено, что значения $\rho$ пленок УКТ на несколько порядков выше, чем $\rho$ пленок PEDOT: PSS. Показано, что с ростом содержания УКТ в композитах PEDOT: PSS-CQDs в зависимостях $\rho(T)$ наблюдается переход от больших значений энергии активации $(\sim 17-18 \mathrm{meV})$, характерных для чистого PEDOT:PSS, к меньшим ее значениям $(\sim 10 \mathrm{meV})$, наблюдаемым в пленках УКТ. Рассмотрен механизм транспорта носителей заряда в исследованных материалах.
\end{abstract}

Ключевые слова:углеродные квантовые точки, проводящие полимеры, композитные пленки, электропроводность.

DOI: $10.21883 /$ FTT.2021.08.51176.090

\section{1. Введение}

Углеродные квантовые точки (УКТ; carbon quantum dots - CQDs) привлекли внимание исследователей в мире благодаря своим уникальным электронным и оптическим свойствам по сравнению с молекулами флуоресцентных красителей и обычными полупроводниковыми квантовыми точками. К преимуществам УКТ можно отнести возможность перестройки ширины запрещенной зоны, высокий квантовый выход фотолюминесценции (ФЛ), биосовместимость, растворимость в воде, а также отличную стабильность и низкую токсичность [1-3]. Оптические свойства УКТ, такие как перестраиваемая ФЛ в диапазоне от глубокого ультрафиолета до ближнего инфракрасного, а также эффективное многофотонное преобразование, обусловлены возможностью модификации УКТ по размеру, форме, поверхностным функциональным группам и легированием гетероатомами [4]. Эти уникальные свойства дают возможность реализовать широкий круг потенциальных биологических и оптоэлектронных применений УКТ, таких как визуализация клеток, терапия рака и доставка лекарств, транспортные и активные слои оптоэлектронных приборов [5]. Высокая термическая и экологическая стабильность УКТ позволяют увеличивать срок службы биопрепаратов и оптоэлектронных приборов на их основе [1-5]. Оптические свойства УКТ, а также их биомедицинские применения в качестве эффективных средств точечной доставки лекарств в настоящее время достаточно широко исследованы [6]. Однако, электронные свойства, в особенности в области низких температур, пленок УКТ и их композитов с проводящими полимерами, такими как PEDOT:PSS, не были описаны и исследованы до настоящего времени.

Целью настоящей работы является синтез УКТ гидротермальным методом из глюкозы, получение пленок УКТ и композитов УКТ с проводящим полимером PEDOT:PSS, а также исследование их электрических свойств в диапазоне температур 77-280 К для определения особенностей транспорта носителей заряда в таких структурах. В результате проведенных исследований показано, что пленки УКТ и PEDOT:PSS-CQDs имеют глобулярную структуру с размерами глобул $\sim 50 \mathrm{~nm}$. Получены зависимости удельного сопротивления от температуры, $\rho(T)$, для пленок УКТ, PEDOT : PSS-CQDs и PEDOT:PSS, имеющие слабый активационный характер. Установлено, что с ростом содержания УКТ в композитах PEDOT:PSS-CQDs в зависимостях $\rho(T)$ наблюдается переход от относительно больших значений энергии активации ( 17-18 meV), характерных для чистого PEDOT:PSS к меньшим ее значениям $(\sim 10 \mathrm{meV})$ наблюдаемых в пленках УКТ. 


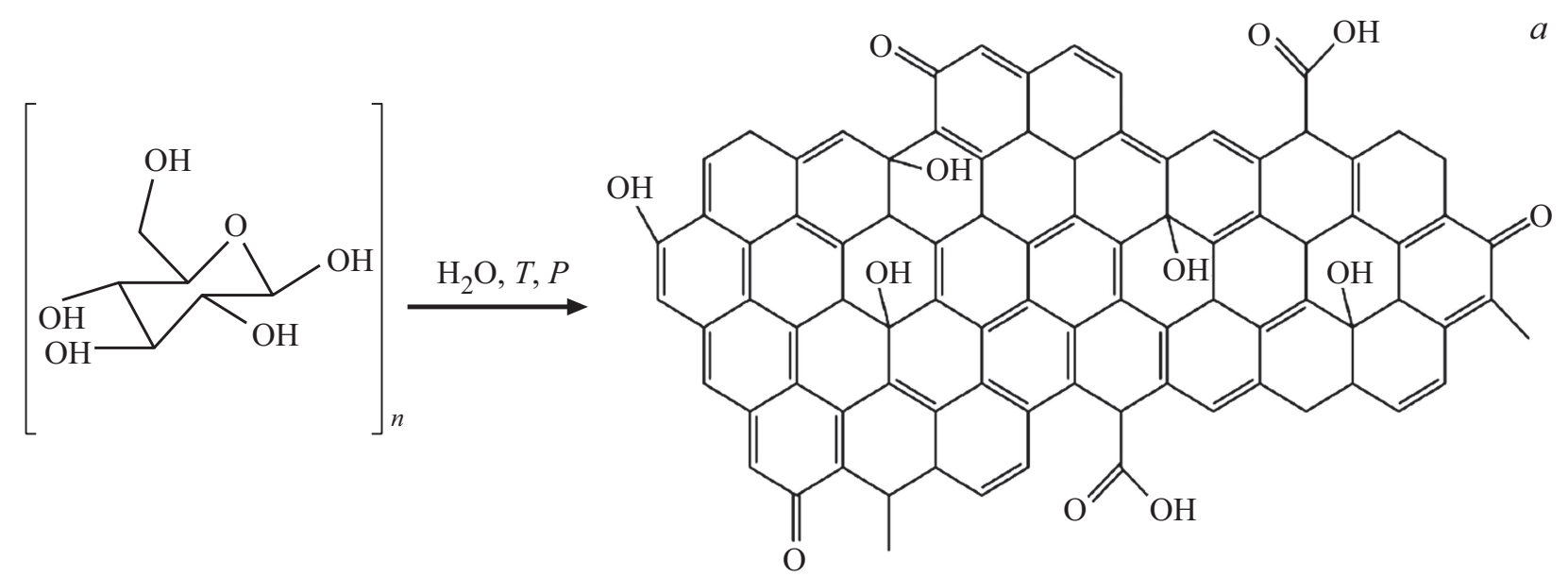
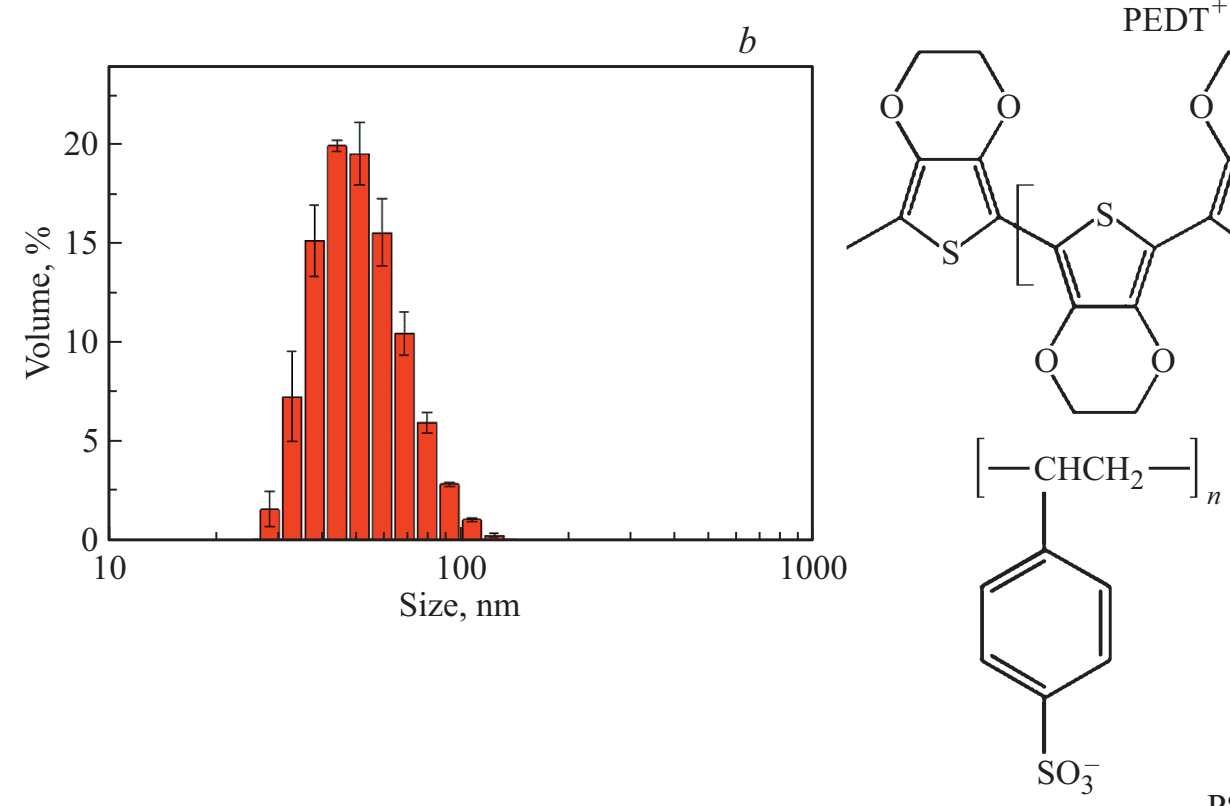

$\mathrm{PSS}^{-}$

Рис. 1. Химический процесс перехода глюкозы в УКТ при гидротермальном синтезе (где функциональные группы обусловливают диспергирование графеноподобных структур в воде) $(a)$, распределение УКТ по размерам $(b)$, структура проводящего полимерного комплекса PEDOT:PSS $(c)$.

\section{2. Объекты и методы исследования}

Углеродные квантовые точки были синтезированы гидротермальным методом из глюкозы $\left(\mathrm{C}_{6} \mathrm{H}_{12} \mathrm{O}_{6}\right.$, Вектон, Россия), исходно, $2.7 \mathrm{~g}$ глюкозы растворяли в $15 \mathrm{ml}$ воды, затем, полученный раствор был перелит в тефлоновый вкладыш и помещен в стальной миниавтоклав для гидротермального синтеза при $T=160^{\circ} \mathrm{C}$ в течение $t=6 \mathrm{~h}$. После синтеза, для удаления крупных частиц, полученный раствор УКТ центрифугировали при 4000 об/мин в течение $10 \mathrm{~min}$, а для дополнительной очистки супернатанта от побочных продуктов реакций, использовали водный диализ через диализную мембрану $(12 \mathrm{kDa})$ длительностью 5 дней с ежедневной заменой воды. На рис. 1, $a$, показан химический процесс образования УКТ из глюкозы при гидротермальном синтезе.
Размеры УКТ определяли с помощью анализатора Zetasizer Nano ZS (модель ZEN3600, Malvern Instruments, United Kingdom). Средний размер частиц составил от 35 до $56 \mathrm{~nm}$, где максимум лежал в диапазоне от 40 до $50 \mathrm{~nm}$ (распределение частиц УКТ по размерам показано на рис. $1, b$, представленное распределение является результатом усреднения трех измерений). Раствор УКТ наносили на кремниевую подложку (КДБ-10) методом полива, после чего образец высушивался при $100^{\circ} \mathrm{C}$ в течение $10 \mathrm{~min}$, а затем выдерживался в вакуумном эксикаторе до проведения измерений. Для приготовления образцов композитов УКТ была использована водная дисперсия проводящего полимера с массовой долей PEDOT: $\mathrm{PSS}=0.013$ (Sigma Aldrich). На рис. 1, $c$, показана структура проводящего полимерного комплекса PEDOT: PSS. Важно отметить, что все использованные в нашей работе исходные компоненты являлись водными 

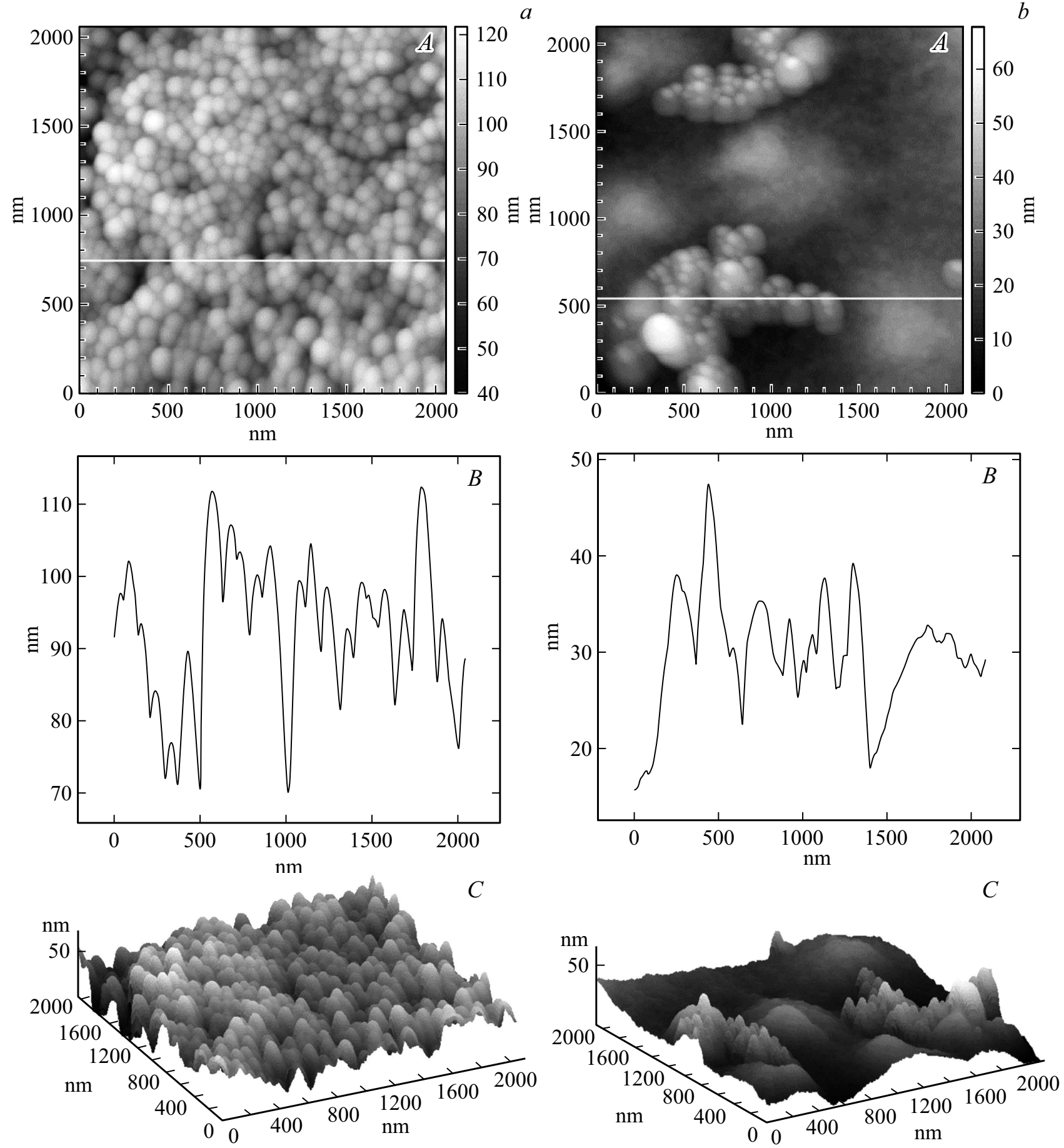

Рис. 2. Результаты АСМ исследований морфологии пленок УКТ $(A, B, C)(a)$ и PEDOT: PSS-CQDs $(0.5: 0.5)(A, B, C)(b)$.

дисперсиями, что обеспечивало их совместимость при приготовлении растворов композитов.

Для исследования электронных свойств были приготовлены пленки PEDOT:PSS-CQDs с различным содержанием УКТ. В качестве подложек использовались стеклянные подложки со слоем ITO (Sigma Aldrich) Расстояние между планарными ITO электродами составляло $\sim 200 \mu \mathrm{m}$, ширина электродов $\sim 5 \mathrm{~mm}$. Растворы водных дисперсий УКТ и PEDOT: PSS смешивались в со- отношении компонентов PEDOT:PSS-CQDs:УKT-100\%, $0.8: 0.2 ; 0.5: 0.5 ;$ PEDOT:PSS-100\% при $300 \mathrm{~K}$ при помощи ультразвуковой мешалки Bandelin SONOPULS ultrasonic homogenizer при частоте $f=20 \mathrm{kHz}$ в течение 2 min до равномерной консистенции. Полученные растворы наносились на стеклянные подложки с ITO электродами методами полива или центрифугирования на прецизионной центрифуге Chemat Technology spin-coater $\mathrm{KW}-4 \mathrm{~A}(2000 \mathrm{rpm})$ в боксе с инертной $\left(\mathrm{N}_{2}\right)$ атмосферой 
DX-2. Нанесенные на подложки образцы высушивали при помощи нагревателя с контролируемой температурой (Heidolph HG $3001 \mathrm{~K}$ ) при $100^{\circ} \mathrm{C}$ в атмосфере $\mathrm{N}_{2}$ в течение $15 \mathrm{~min}$ в инертном боксе DX-2. Морфология пленок исследовалась с помощью атомно-силового микроскопа (ACM) P47-Solver NT-MDT. Толщина пленок, полученных методом полива, согласно результатам $\mathrm{ACM}$, составила $\sim 0.5-1.0 \mu \mathrm{m}$. Спектры поглощения и ФЛ УКТ, нанесенные на кварцевые подложки, регистрировали с помощью высокочувствительного оптоволоконного спектрометра „AVANTES“ - AvaSpec-ULSi2048LUSB2 OEM, работающего в спектральном диапазоне $322-1100 \mathrm{~nm}$. Вольт-амперные характеристики (BАХ) образцов, помещенных на держатель оптического проточного азотного криостата со стабилизацией температуры OPTCRYO198, измерялись на постоянном токе в атмосфере азота в темноте и при освещении имитатором солнечного света в интервале температур 77-280 K с шагом 10-20 K с использованием автоматизированной измерительной установки на основе пикоамперметра Keithley 6487. Напряжение варьировалось с переменным шагом в пределах от $-5 \mathrm{~V}$ до $+5 \mathrm{~V}$. Электрические контакты к образцам изготовлялись с использованием серебряной проволоки, которая крепилась к металлическим электродам углеродной или серебряной пастой (SPI).

\section{3. Результаты и обсуждение}

Результаты АCM исследований пленок УКТ и PEDOT:PSS-CQDs, представленные на pис. 2, $a(A, B, C)$, свидетельствуют о том, что пленки УКТ имеют развитую поверхность с неоднородной морфологией, которая характеризуется наличием глобул с ярко выраженными границами, при этом средний диаметр зерен для пленок УКТ варьируется в пределах $\sim 50-100 \mathrm{~nm}$, а их высота составляет $\sim 50 \mathrm{~nm}$, что сопоставимо с размерами УКТ. Исследуемые пленки УКТ характеризуются значительной шероховатостью (Root Mean Square, $R_{q}$ ), которая для пленок УКТ в поле $2 \times 2 \mu \mathrm{m}$ составила $R_{q} \sim 10.6 \mathrm{~nm}$ (Average Roughness $=20 \mathrm{~nm}$ ) (рис. 2,a). Морфология композитных пленок PEDOT:PSS-CQDs $(0.5: 0.5)$, как следует из рис. $2, b(A, B, C)$, является более сложной по сравнению с пленками УКТ. В исследуемом композите PEDOT: PSS-CQDs $(0.5: 0.5)$ наблюдаются агломераты (до $1000 \mathrm{~nm}$ ) из глобул (до $100 \mathrm{~nm}$ ) УКТ, которые распределены в матрице PEDOT:PSS неравномерно, оставляя свободные от УКТ участки поверхности полимера PEDOT:PSS, при этом в поле $2 \times 2 \mu \mathrm{m}$ $R_{q} \sim 8.85 \mathrm{~nm} \quad$ (Average $\quad$ Roughness $=7.0 \mathrm{~nm}$ ), что меньше, чем эти же параметры для пленок чистых УКТ.

Спектры поглощения и ФЛ пленок УКТ и PEDOT:PSS-CQDs $(0.5: 0.5)$ показаны на рис. 3, $a$ и $b$, соответственно. Как видно из рис. $3, a$, край поглощения и максимум ФЛ пленок УКТ соответствуют длине волны $720 \mathrm{~nm}$, после которого идет плавный
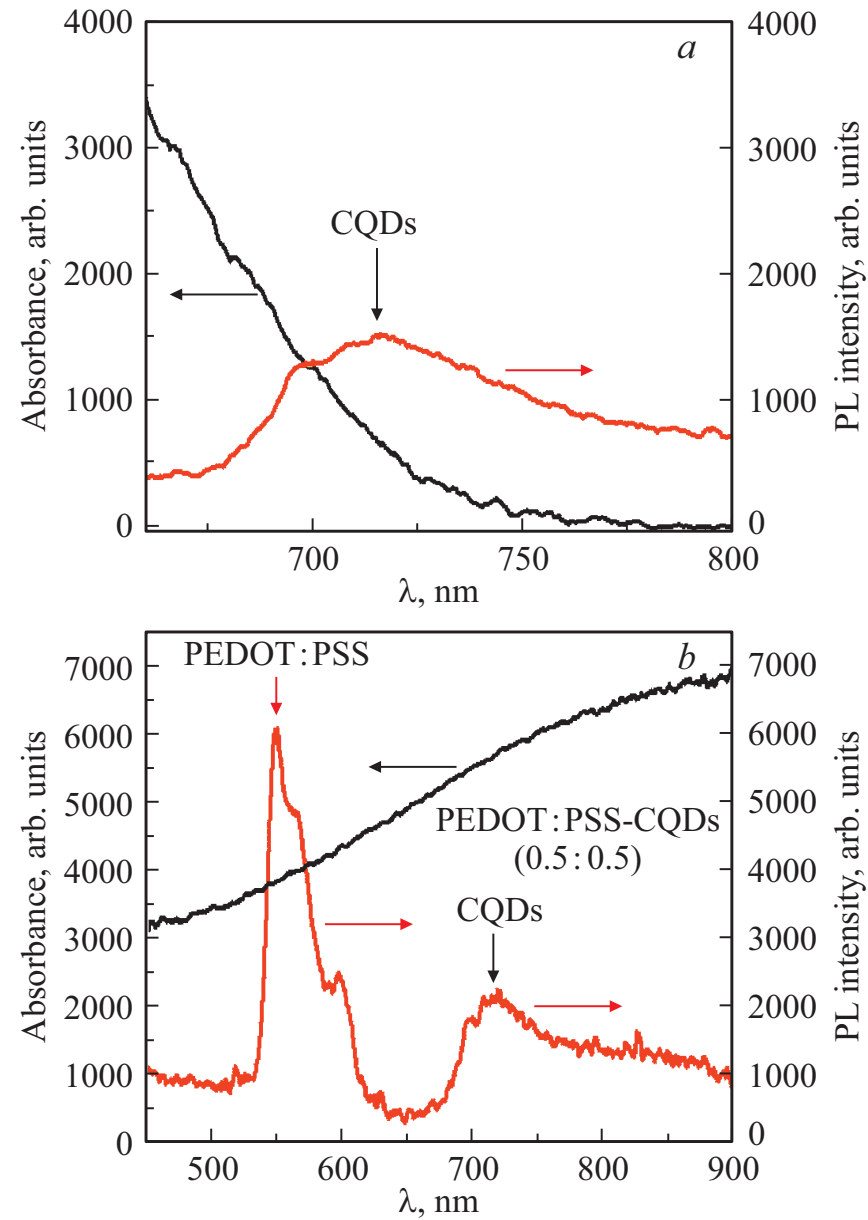

Рис. 3. Спектры поглощения и ФЛ пленок УКТ $(a)$ и PEDOT: PSS-CQDs $(0.5: 0.5)(b)$.

спад интенсивности ФЛ. Таким образом, можно оценить ширину запрещенной зоны исследуемых УКТ как $E_{g} \sim 1.72 \mathrm{eV}$. Спектры поглощения и ФЛ пленок PEDOT:PSS-CQDs $(0.5: 0.5)$ имеют более сложный характер (рис. $3, b)$. Как видно из рис. $3, b$, поглощение таких пленок растет с ростом длины волны, что характерно для спектров поглощения чистого PEDOT:PSS [7], тогда как спектры ФЛ содержат вклады от обоих компонентов композита: УКТ и PEDOT:PSS с максимумами ФЛ при $\sim 720 \mathrm{~nm}$ и $550 \mathrm{~nm}$, соответственно.

BAX пленок УКТ (a) и PEDOT:PSS-CQDs $(0.5: 05)(b)$ при прямом и обратном смещении в линейном и полулогарифмическом масштабах, при различных температурах представлены на рис. 4, $a, b$. Из рис. 4, $a$ следует, что ВАХ пленок УКТ имеют нелинейный характер как при прямом, так и при обратном смещении. В то же время ВАХ пленок PEDOT:PSS-CQDs (0.5: 05) (рис. 4, $b$ ) демонстрируют хорошую линейность во всем интервале напряжений и температур. При этом значения $\rho(280 \mathrm{~K})$ пленок PEDOT:PSS-CQDs на несколько порядков ниже, чем $\rho(280 \mathrm{~K})$ пленок УКТ. При облучении образцов пленок 

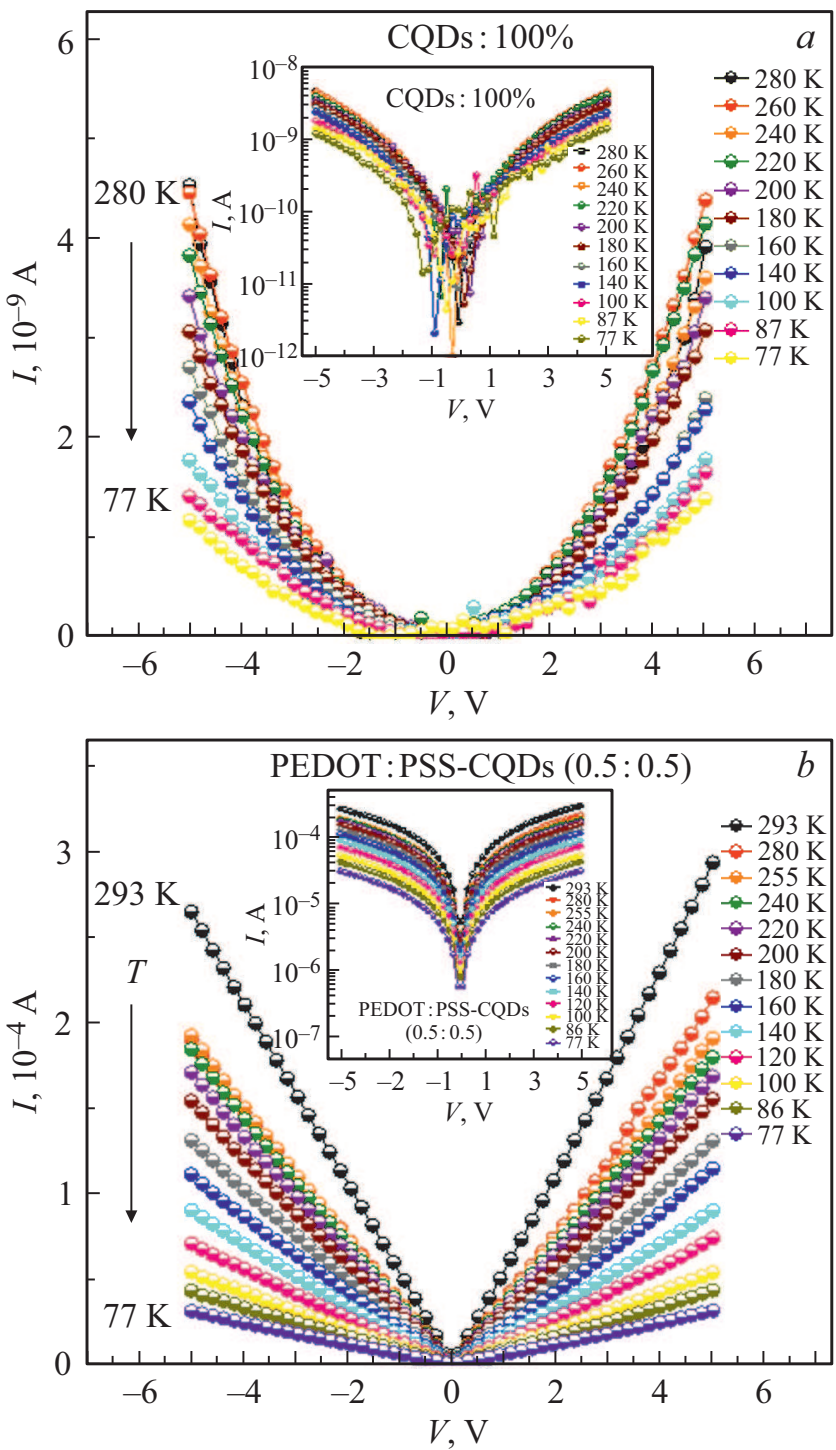

Рис. 4. Вольт-амперная характеристика пленок УКТ $(a)$ и PEDOT:PSS-CQDs $(0.5: 0.5)(b)$ при прямом и обратном смещении в линейном и полулогарифмическом масштабах, при различных температурах.

УКТ и PEDOT:PSS-CQDs $(0.5: 05)$ имитатором солнечного света с длиной волны в диапазоне 300-700 nm не было обнаружено заметного фототока, что свидетельствует о том, что УКТ и PEDOT: PSS-CQDs $(0.5: 05)$ не обладают заметной фотопроводимостью в видимом спектральном диапазоне. Установлено, что пленка УКТ имеет высокое удельное сопротивление $\left(\sim 2 \cdot 10^{7} \Omega \cdot \mathrm{cm}\right)$ при температуре $280 \mathrm{~K}$, которое увеличивается с понижением температуры $\left(\sim 7 \cdot 10^{7} \Omega \cdot \mathrm{cm}\right.$ при $\left.T=87 \mathrm{~K}\right)$. При этом удельное сопротивление пленок PEDOT:PSS-CQDs $(0.5: 05)$ при $280 \mathrm{~K}$ составило $\sim 10^{2}-10^{3} \Omega \cdot \mathrm{cm}$, что ниже чем у пленок УКТ на 4-5 порядков, что, наряду с хорошей линейностью ВАХ, является характеристикой перспективной для приборных применений.
На основании ВАХ были построены зависимости удельного сопротивления $\rho(T)$ пленок УКТ, PEDOT:PSS-CQDs и PEDOT:PSS от обратной температуры, представленные на рис. 5. Как следует из рис. 5, зависимости $\rho(T)$ имеют слабый активационный характер и могут быть описаны выражением

$$
\rho(T)=\rho_{0} \exp \left(E_{a} / k_{B} T\right),
$$

где: $E_{a}-$ энергия активации, $T-$ температура, $k_{B}-$ постоянная Больцмана. Энергия активации проводимости, $E_{a}$, вычислялась из температурных зависимостей $\rho(T)$ по формуле: $E_{a}(\mathrm{meV})=(200 \Delta \lg \rho) /(\Delta 1000 / T)$, где $\rho$ - удельное сопротивление пленки.

Установлено, что с ростом содержания УКТ в композитах PEDOT: PSS-CQDs наблюдается рост абсолютных значений $\rho$, а в зависимостях $\rho(T)$ наблюдается переход от больших значений энергии активации ( 17-18 meV), характерных для PEDOT: PSS к меньшим ее значениям $(\sim 10 \mathrm{meV})$ характерным для пленок УКТ. Таким образом, полученные значения $E_{a}$ составили $\sim 10-18 \mathrm{meV}$, что, на наш взгляд, свидетельствует о прыжковой проводимости носителей заряда между примесными состояниями внутри запрещенной зоны. Наблюдаемые близкие значения $E_{a}$ в исследуемых композитных пленках PEDOT: PSS-CQDs с различным содержанием УКТ можно объяснить тем, что агломераты УКТ распределены в матрице PEDOT:PSS неравномерно, что приводит к наличию свободных от УКТ участков поверхности проводящего полимера PEDOT:PSS, по которым, по нашему мнению, и происходит основной транспорт носителей заряда в таких системах. На рис. 6 показаны зависимости удельного сопротивления от времени хранения пленок УКТ, PEDOT:PSS-CQDs и PEDOT:PSS, из которых следу-

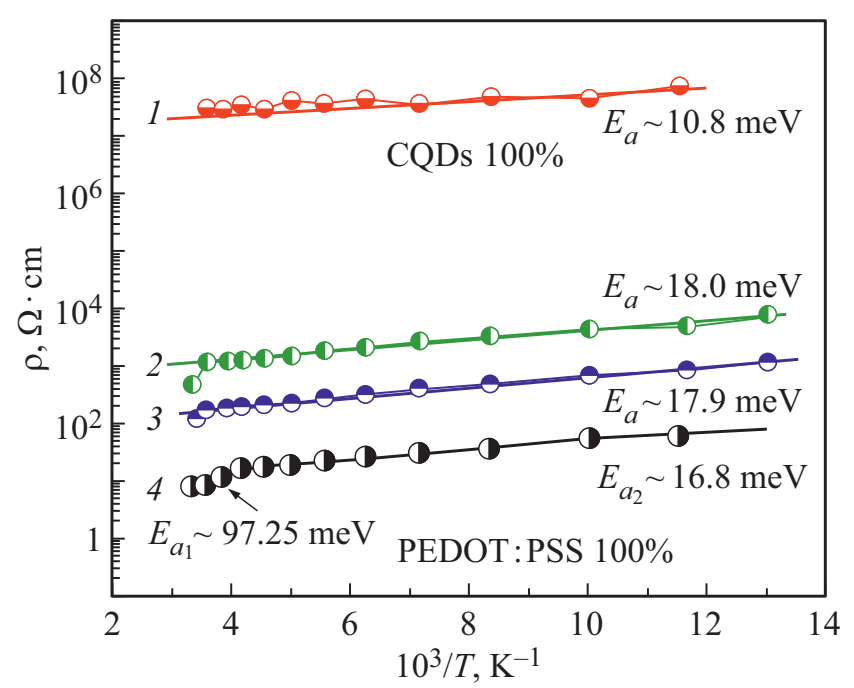

Рис. 5. Зависимости удельного сопротивления от обратной температуры исследуемых пленок: 1 - УКТ 100\%, 2 - PEDOT:PSS-CQDs $(0.8: 0.2), 3$ - PEDOT:PSS-CQDs $(0.5: 0.5), 4-$ PEDOT:PSS $100 \%$. 


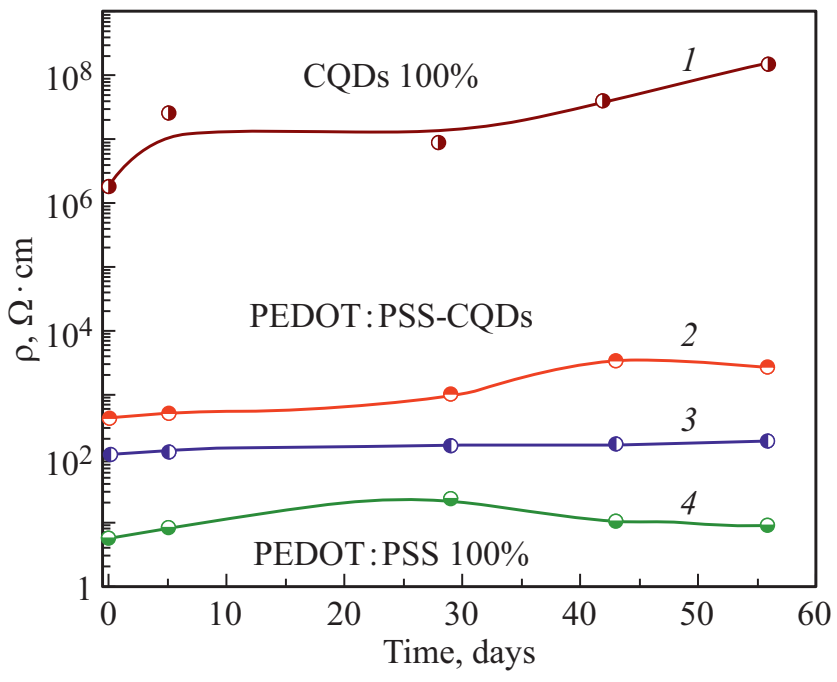

Рис. 6. Зависимости удельного сопротивления от времени хранения пленок УКТ, PEDOT:PSS-CQDs с различным содержанием УКТ и PEDOT:PSS: 1 - УКТ 100\%; 2 - PEDOT:PSS-CQDs $(0.8: 0.2) ; 3$ - PEDOT:PSS-CQDs $(0.5: 0.5) ; 4-$ PEDOT:PSS $100 \%$.

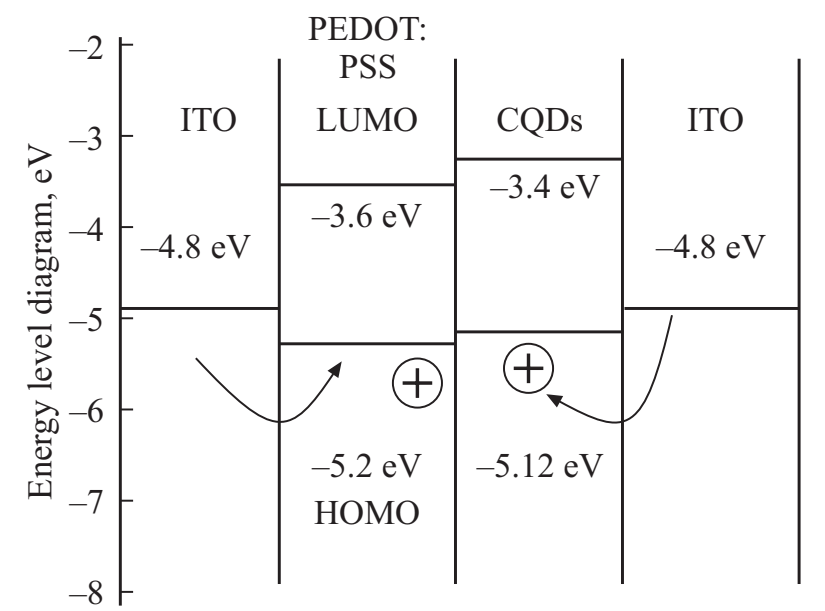

Рис. 7. Зонная диаграмма структуры ITO/PEDOT:PSSCQDs/ITO.

ет, что все исследованные образцы обладают хорошей стабильностью электронных свойств (удельного сопротивления), включая пленки УКТ и PEDOT:PSS. Среди композитных пленок PEDOT:PSS-CQDs наилучшие результаты по стабильности $\rho$ демонстрировали пленки PEDOT:PSS-CQDs $(0.5: 05)$. При этом важно еще раз отметить, что удельное сопротивление композитных пленок PEDOT:PSS-CQDs $(0.8: 0.2 ; 0.5: 0.5)$ ниже на 3-4 порядка, чем удельное сопротивление пленок УКТ. На рис. 7 показана зонная диаграмма структуры glass/ITO/PEDOT:PSS-CQDs/ITO, исследованная в настоящей работе. Как следует из рис. 7, пленки УКТ и композитов PEDOT: PSS-CQDs являются эффективным дырочным транспортным материалом, что, наряду с хорошей стабильностью, делает их перспективными для применения в качестве дырочных транспортных слоев в органических и перовскитных солнечных элементах [8], а также в других приборах гибкой органической электроники.

\section{4. Заключение}

Гидротермальным методом синтезированы УКТ из глюкозы и получены их композиты с проводящим полимером PEDOT:PSS; исследованы их электрические свойства в диапазоне температур 77-280 K. Показано, что пленки УКТ и PEDOT:PSS-CQDs имеют глобулярную структуру с размерами глобул $\sim 50 \mathrm{~nm}$. Получены зависимости удельного сопротивления от температуры, $\rho(T)$, для пленок УКТ и PEDOT:PSS-CQDs, имеющие слабый активационный характер. Установлено, что с ростом содержания УКТ в композитах PEDOT:PSS-CQDs в зависимостях $\rho(T)$ наблюдается переход от больших значений энергии активации ( 17-18 meV), характерных для чистого PEDOT:PSS, к меньшим ее значениям $(\sim 10 \mathrm{meV})$, наблюдаемым в пленках УКТ, что свидетельствует о прыжковой проводимости носителей заряда между примесными состояниями внутри запрещенной зоны в исследованных материалах. Пленки УКТ и композитов PEDOT:PSS-CQDs являются перспективными для применения в качестве стабильных дырочных транспортных слоев в приборах гибкой органической электроники.

\section{Благодарности}

Авторы благодарны НИЛ нанотехнологий ЦЭБ ИЭМ ФГБУ „НМИЦ им. В.А. Алмазова“ МР, Санкт-Петербург, Россия, а также Р.С. Крюкову за помощь в синтезе УКТ.

\section{Конфликт интересов}

Авторы заявляют, что у них нет конфликта интересов.

\section{Список литературы}

[1] T. Yuan, T. Meng, P. He, Y.X. Shi, Y. Li, X. Li, L. Fan, S. Yang. J. Mater. Chem. C. 7, 6820 (2019).

[2] R. Wang, K.Q. Lu, Z.R. Tang, Y.J. Xu. J. Mater. Chem. A 5, 3717 (2017).

[3] S.Y. Lim, W. Shen, Z. Gao. Chem. Soc. Rev. 44, 362 (2015).

[4] Y.B. Yan, J. Gong, J. Chen, Z.P. Zeng., W. Huang, K.Y. Pu, J.Y. Liu, P. Chen. Adv. Mater. 31, 211808283 (2019).

[5] X.T. Zheng, A. Ananthanarayanan, K.Q. Luo, P. Chen. Small. 11, 1620 (2015).

[6] M.J. Molaei. RSC Adv. 9, 6460 (2019).

[7] A.N. Aleshin, A.S. Berestennikov, P.S. Krylov, I.P. Shcherbakov, V.N. Petrov, I.N. Trapeznikova, R.I. Mamalimov, A.K. Khripunov, A.A. Tkachenko. Synthetic Met. 199, 147 (2015).

[8] S. Paulo, G. Stoica, W. Cambarau, E. Martinez-Ferrero, E. Palomares. Synthetic Met. 222, 17 (2016).

Редактор Ю.Э. Китаев 